\title{
The Powertrain of Tomorrow
}

Dear Reader,

The MTZ Symposium in Wolfsburg, "The Powertrain of Tomorrow", established over a decade ago with the support of Volkswagen and Schaeffler, took a hiatus this year. Pausing, to restart at full speed in 2017. The increasing electrification of drive systems and $\mathrm{CO}_{2}$-neutral fuels that will be required in future lead to a level of complexity when developing drive systems and vehicles as a whole that requires a more intensive and systemic approach to planning, processes and procedures. With this in mind, we are working with our existing partners to address the interplay of the combustion engine, transmission and electrification and give "The Powertrain of Tomorrow” new strategic momentum. This issue includes a special section as a foretaste to the symposium. We would be delighted to have the pleasure of welcoming you as a presenter or visitor in Frankfurt am Main on 25 and 26 January 2017.

Legislation governing $\mathrm{CO}_{2}$ emissions and air quality has transformed the circumstances under which future drive systems are developed. The shift in social values increasingly means that one of the key criteria for success or failure will be how large the ecological footprint of a vehicle, and hence the brand, ultimately is. Introducing WLTP will go a long way towards closing what is now a large gap between real consumption and the consumption figures indicated in the catalogue. So-called worst-case $\mathrm{CO}_{2}$ figures will become mandatory, and separate $\mathrm{CO}_{2}$ figures will be allowed for individual vehicles and variants. This will also mean having to optimise optional equipment. A longer cycle, greater acceleration and higher speed will reflect a far more realistic driving cycle. This will reduce the impact of electrical components and increase the contribution of drag.

The RDE subject is very complex, since general parameters like environmental factors, route, driving style and fuels all play major roles in everyday driving. RDE ceased to be an issue with commercial vehicles several years ago but they remain significant for passenger vehicles because of the enormous excess power. The influence of the driver far exceeds that of the route and is even greater in the case of SUVs than other types of vehicle. This may mean the need for particulate filters on gasoline engines as well, to maximise the robustness of RDE. Given this fact begs the question once again as to why the so-called "nice guy" among gasoline engines - the CNG drive - still struggles to gain acceptance.

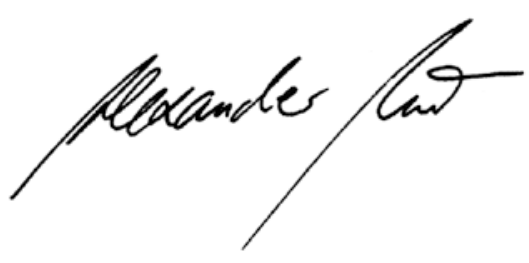

Dr. Alexander Heintzel Editor in Chief

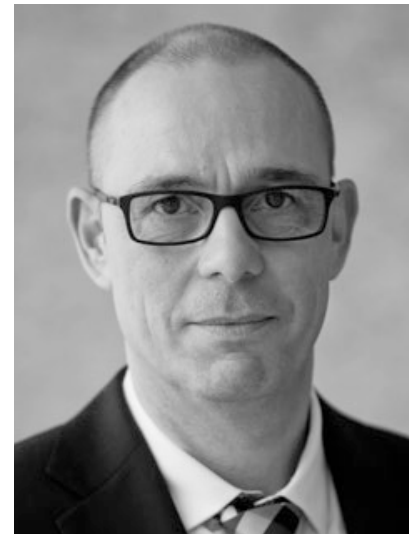

